\title{
The effects of picloram and 2,4-dichlorophenoxyacetic acid on induction of red coloured callus from celosia plumosa, an attractive ornamental plant
}

\author{
Noraini Mahmad ${ }^{1}$, Rosna Mat Taha ${ }^{2, *}$, Norlina Rawi $^{3}$, Sadegh Mohajer ${ }^{4}$ \\ 1,2,3, I Institute of Biological Sciences, Faculty of Science, University of Malaya, 50603 Kuala Lumpur, \\ Malaysia
}

\section{Index Terms}

Celosia

Leaf Explants

Red-Coloured Callus

Root Explants

Stem Explants

Received: 27June 2014

Accepted: 3August 2015

Published: 15 October 2015

\begin{abstract}
Celosia plumosais an attractive ornamental plant having flame-like flowers and is used traditionally as a medicinal herb. This paper deals with thered-coloured callus induction from the root, stem and leaf explants when cultured on Murashige and Skoog (MS) medium supplemented with different concentrations of auxin picloram and 2,4dichlorophenoxyacetic acid (2,4-D), applied singly. When explants were cultured on MS media supplemented with $6.0 \mathrm{mg} / \mathrm{l}$ picloram, the highest amount of red-coloured callus $(0.49 \pm 0.26 \mathrm{~g})$ was from leaf explants and the lowest $(0.09 \pm 0.02 \mathrm{~g})$ from stem explants. However, the highest amount of red-coloured callus $(0.69 \pm 0.13 \mathrm{~g})$ was achieved on Murashige and Skoog (MS) media supplemented with $1.5 \mathrm{mg} / \mathrm{l}$ 2,4-D from stem explants, while the lowest $(0.13 \pm 0.06 \mathrm{~g})$ from root explants was cultured on $0.5 \mathrm{mg} / \mathrm{l} 2,4$-D. Generally, the optimum concentration for red-coloured callus formation using picloram ( $6.0 \mathrm{mg} / \mathrm{l})$ was higher compared to 2,4-D (1.5 mg/l 2,4-D).
\end{abstract}

(C) 2015 The Author(s). Published by TAF Publishing.

\section{INTRODUCTION}

Celosia plumosa is a herbaceous plant and has been classified as a member of the family Amaranthaceae. This annual plant has a distinctive characteristic inflorescence which looks like the crest of a rooster or convoluted brain after it has developed fully [1]. Generally, the flower colours include red, yellow, orange and pink. The Celosia plant are erect, branching plants with oval or lanceshaped, strongly veined leaves that are 2-6 inch (5.1-15.2 $\mathrm{cm}$ ) long and hundreds of tiny flowers packed in dense, brightlycoloured flower heads which usually stand above the foliage.

The flowers have the following characteristics; acrid, astringent, styptic, depurative, uterine sedative, constipating, antibacterial, corrective of urinary pigments, febrifuge and alexeteric. They are useful in the conditions of kapha and pitta, leprosy, burning sensation, skin diseases, diarrhoea, dysentery, fever, headache, hemorrhoids, herpes, internal hemorrhage, leucorrhea, liver disorders, menorrhagia, ulcers and wounds. Juice of leaves is used in bilious sickness. They are also valued as a stimulant in pregnancy. The seed is hypotensive and ophthalmic. It is used in the treatment of bloodshot eyes, blurring of vision, cataracts and hypertension. The flower 
and seed are astringent, haemostatic, parasiticide and poultice. It is used in the treatment of bloody stool, haemorrhoid bleeding, uterine bleeding, leucorrhoea and diarrhoea.

The aim of the present study is to investigate the effects of picloram and 2,4-dichlorophenoxyacetic acid, and also to determine the optimum medium for in-vitro red coloured callus formation from root, stem and leaf explants.

\section{MATERIALS AND METHOD}

i) Plant materials and tissue culture initiation

Celosia plumosa is native to South America and widespread in Asia, especially, Malaysia. The seeds were initially washed with tap water and teepol to remove impurities and microorganisms on the seed surface. The seeds were then sterilized with $99 \%$ (v/v) sodium hypochlorite and added with two drops of tween-20 for five minutes. The seeds were then soaked in $70 \%, 50 \%$, $30 \%$ and $20 \%(\mathrm{v} / \mathrm{v})$ sodium hypochlorite for 5 minutes one by one. Then, the seeds were rinsed with distilled water for three times [2]. In laminar flow chamber, the seeds were dipped in $70 \%(\mathrm{v} / \mathrm{v})$ ethanol for 1 minute and rinsed with sterile distilled water for three times. Seeds were cultured on solid basal germination medium composed of [3] salts and vitamins supplemented with $30 \mathrm{~g} / \mathrm{L}$ sucrose and $10 \mathrm{~g} / \mathrm{L}$ agar. One-month-old aseptic seedlings were used as explant sources. The explants were excised into small pieces $(3 \mathrm{~mm} 2)$ and cultured on MS media supplemented with picloram and 2,4dichlorophenoxyacetic acid (2,4D), with 30 replicates for each treatment. Media were adjusted to $\mathrm{pH} 5.5$ and sterilized by autoclaving (15 $\mathrm{min}, 121^{\circ} \mathrm{C}$ ) and $50 \mathrm{ml}$ aliquots were dispensed into pre-sterilized $290 \mathrm{ml}$ plastic bottles ( $80 \mathrm{~mm}$ diameter x $60 \mathrm{~mm}$ high). All cultures were incubated in a growth room at $24^{\circ} \mathrm{C}$ day and night temperature, with a 16 -h photoperiod at 80-85 $\mu \mathrm{mol} \mathrm{m-2}$ s-1 under cool white fluorescent light.

\section{A. Callus Induction}

Celosia plumos were cultured on MS medium [3], supplemented with various concentrations of plant growth regulators (Picloram and 2,4-D) for red-coloured callus induction and plant regeneration. The callus cultures were maintained at $25 \pm 1^{\circ} \mathrm{C}$, under 16 hours light of photoperiod with $25 \mu \mathrm{mol} \mathrm{m}-2 \mathrm{~s}-2$ of light intensity. At regular intervals for all treatments, each callus was harvested carefully by separating from media using spatula, and fresh and dry weight was recorded for each.

TABLE I

EFFECT OF PICLORAM ON THE FORMATION OF CALLUS FROM EXPLANTS (ROOT, STEM AND LEAF) OF CELOSIA PLUMOSA

\begin{tabular}{llll}
\hline \hline $\begin{array}{l}\text { Picloram } \\
\text { Concentration }(\mathrm{mg} / \mathrm{l})\end{array}$ & Explants & $\begin{array}{l}\text { Dried weight of callus,g } \\
(\text { Mean } \pm \text { SE) }\end{array}$ & Observation \\
\hline 2.0 & Root & - & No callus formation \\
& Stem & $0.08 \pm 0.03$ & $\begin{array}{l}\text { Cream-coloured callus formation } \\
\text { Red-coloured callus formation }\end{array}$ \\
& Leaf & $0.25 \pm 0.11$ & No callus formation \\
4.0 & Root & - & Red-coloured callus formation \\
& Stem & $0.15 \pm 0.07$ & Red-coloured callus formation \\
6.0 & Leaf & $0.24 \pm 0.19$ & Red and cream callus formation \\
& Root & $0.16 \pm 0.10$ & Red and cream callus formation \\
& Stem & $0.09 \pm 0.02$ & Red-coloured callus formation \\
& Leaf & $0.49 \pm 0.26$ & Red and cream callus formation \\
& Root & $0.10 \pm 0.07$ & Red and cream callus formation \\
& Stem & $0.37 \pm 0.19$ & Red-coloured callus formation \\
\hline \hline
\end{tabular}

\section{RESULTS AND DISCUSSION}

[4]Through invitro methods, the effect of the seasons can be eliminated and year-round production can be achieved, or a new cultivar can be produced commercially at a faster rate. Table 1 shows the effects of picloram on red-coloured callus induction from root, stem and leaf explants. Leaf was the optimum explant with the highest $(0.49 \pm 0.26 \mathrm{~g})$ 
dried weight of red coloured callus cultured on Murashige and Skoog (MS) media supplemented with $6.0 \mathrm{mg} / \mathrm{l}$ picloram, followed by MS media supplemented with 8.0 $\mathrm{mg} / \mathrm{l}$ picloram $(0.38 \pm 0.07 \mathrm{~g})$. Whilst, the lowestdried weight of callus $(0.09 \pm 0.02 \mathrm{~g})$ was obtained fromstem explants cultured on MS media supplemented with 6.0 $\mathrm{mg} / \mathrm{l}$ picloram.

TABLE II

EFFECT OF 2,4-D ON THE FORMATION OF CALLUS FROM EXPLANTS (ROOT, STEM AND LEAF) OF CELOSIA PLUMOSA

\begin{tabular}{llll}
\hline \hline $\begin{array}{l}\text { 2,4-D Concentration } \\
(\mathrm{mg} / \mathrm{l})\end{array}$ & Explants & $\begin{array}{l}\text { Dried weight of callus,g } \\
(\mathrm{Mean} \pm \mathrm{SE})\end{array}$ & Observations \\
\hline 0.5 & Root & $0.13 \pm 0.06$ & Cream-coloured callus formation \\
& Stem & $0.55 \pm 0.10$ & Red and cream callus formation \\
& Leaf & $0.50 \pm 0.04$ & Red-coloured callus formation \\
1.0 & Root & $0.27 \pm 0.10$ & Red and cream callus formation \\
& Stem & $0.42 \pm 0.10$ & Red-coloured callus formation \\
& Leaf & $0.45 \pm 0.30$ & Red-coloured callus formation \\
1.5 & Root & $0.17 \pm 0.03$ & Red-coloured callus formation \\
& Stem & $0.69 \pm 0.13$ & Red-coloured callus formation \\
& Leaf & $0.39 \pm 0.08$ & Red-coloured callus formation \\
2.0 & Root & $0.26 \pm 0.14$ & Red and cream callus formation \\
& Stem & $0.48 \pm 0.06$ & Red-coloured callus formation \\
& Leaf & $0.37 \pm 0.17$ & Red-coloured callus formation \\
\hline \hline
\end{tabular}

Table 2 shows that the highest $(0.69 \pm 0.13 \mathrm{~g})$ red-coloured callus formation was achieved on MS media supplemented with $1.5 \mathrm{mg} / \mathrm{l}$ 2,4-D from stem explant (Figure 1), while the lowest amount of callus $(0.13 \pm 0.06)$ was obtained from root explants. Generally, 2,4-D gave the better response in forming red-coloured callus from stem explants as compared to leaf explants cultured on picloram, as found in the current study.
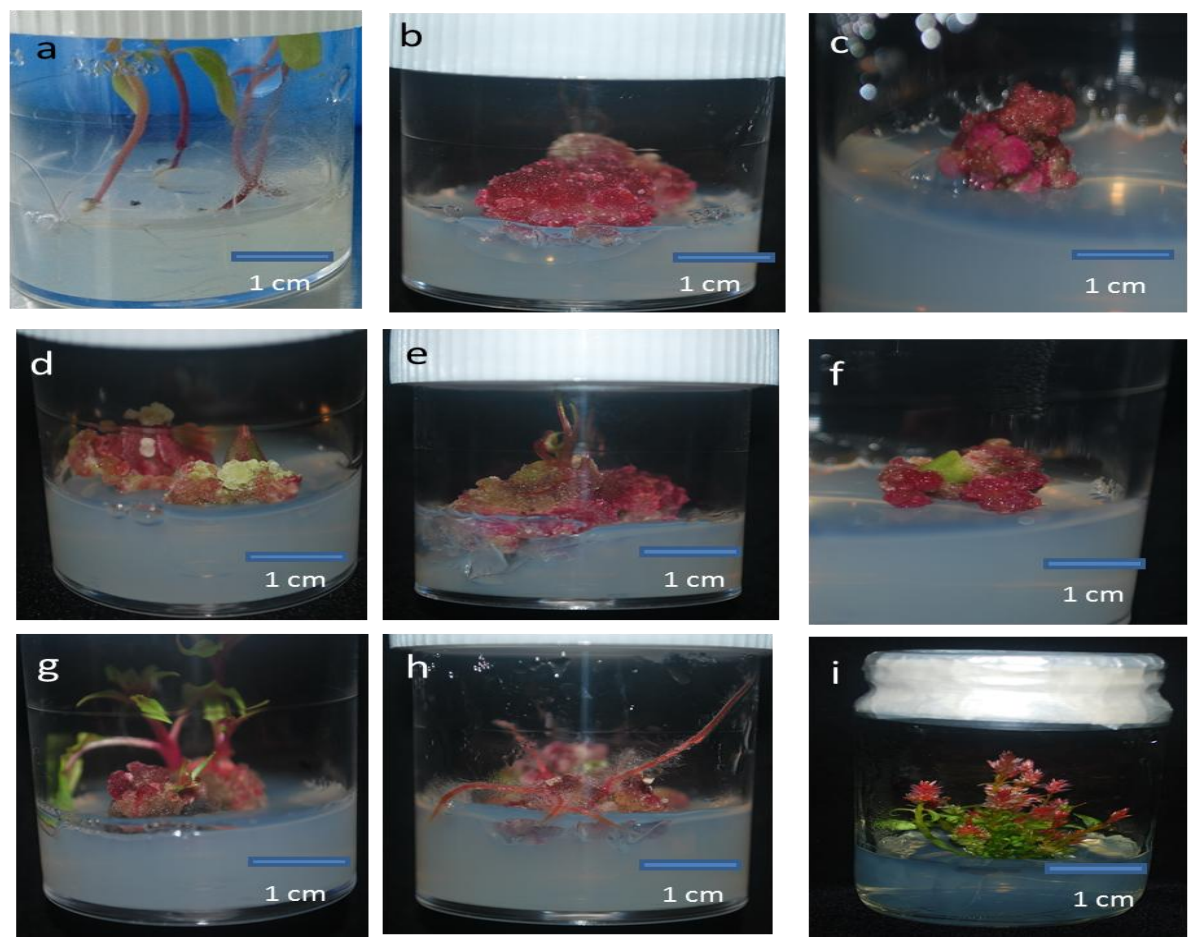

Fig 1. Formation of red-coloured callus on Murashige and Skoog (MS) media. 
Supplemented with $1.5 \mathrm{mg} / \mathrm{l}$ 2,4-D from stem explants. a) one-month old in-vitro seed germination b) red-coloured friable callus formation after 3 weeks c) red-coloured compact callus after 8 weeks d) red micro-shoot formation after 10 weeks e) elongated red micro-shoots f) green micro-shoots) elongated multiple shoots $h$ ) root formation i) in-vitro flowering after 10 months.

[5] Reported that explants from stem segments of Celosia spp. formed callus when cultured on media containing either half strength MS or without MS combined with $100 \mathrm{~g} / \mathrm{l}$ each gelling agent and $70 \mathrm{ml} / \mathrm{l}$ coconut water. Also, in-vitro flowering of Celosia cristata was reported by [6]. [7] The highest amount of reddish callus was obtained when stem explants were cultured on MS media supplemented with 0.5-1.0 mg/l 1Naphthaleneacetic acid (NAA) and 0.5-1.0 mg/l 6Benzylaminopurine (BAP) after 3 weeks. Celosia spp. are amenable in tissue culture and all C. crispate explant sources could regenerate or were able to produce shoots in-vitro [2] whereas, in V. Faber, it is comparatively more difficult to induce callus and regeneration in-vitro [8].

\section{CONCLUSION}

The highest amount of red-coloured callus $(0.69 \pm 0.13$ g) was achieved on MS media supplemented with 1.5 $\mathrm{mg} / \mathrm{l}$ 2,4-D from stem explants. Whilst, the highest amount of red-coloured callus $(0.49 \pm 0.26 \mathrm{~g})$ was achieved on MS media supplemented with $6.0 \mathrm{mg} / \mathrm{l}$ picloram from leaf explants.

\section{ACKNOWLEDGEMENT}

The authors are grateful to University of Malaya, Malaysia for the facilities provided and Institute of Research Management and Monitoring, IPPP (PG071-2013B) and University Malaya Research Grant, UMRG
(RP025/2012A) .

\section{REFERENCES}

[1] B. Bojian, S. E. Clemants and T. Borsc, Amaranthaceae, in Flora of China, vol. 5., Z. Y. Wu, P. H. Raven and D. Y. Hong, (Eds), St. Louis, MO, USA: Missouri Botanical Garden Press, 2003, pp. 415-29.

[2] R. M. Taha and S. N. Wafa, "Plant regeneration and cellular behaviour studies in Celosia cristata grown in vivo and in vitro," The Scientific World Journal, pp. 1-8, 2012. DOI: doi.org/10.1100/2012/359413

[3] T. Murashige and F. Skoog, "A revised medium for rapid growth and bio assays with tobacco tissue cultures," Physiologia Plant Arum, vol. 15, no. 3, pp. 473-497, 1962.

DOI: $10.1111 /$ j.1399-3054.1962.tb08052.x

[4] R. L. M. Pierik, "In vitro culture of higher plants as a tool in the propagation of horticultural crops," in Int. Symp. Propagation of Ornamental Plants, 1987, pp. 2540.

[5] N. Daud, R. M. Taha, N. N. M. Noor and H. Alimon, "Provision of low cost media options for in vitro culture of Celosia SP," African Journal of Biotechnology, vol. 10, no. 80, pp. 18349-18355, 2013.

[6] R. M. Taha, "In vitro flowering of celosia cristata," Jurnal Sains, vol. 8, no. 1, pp. 1027-1031, 2000.

[7] S. Mohajeri, R. M. Taha, E. Arash Khorasani, M. Noraini and M. Normadiha, " Anthocyanin production, antioxidant potential and antitumor activity of Celosia cristata against HCT 116 cell line," in proc. of Int. Conf. on Innovative Trends in Multidisciplinary Academic Research, 2014, pp. 208-212.

[8] M. Taha, "Studies on the cellular behavior of roots of Vicia Faba L., in vivo and in vitro," Ph.D. thesis, Wales Univ., Cardiff, UK, 1989. 